\title{
Establishment of a System Suitable for Analysis of Balanced and Unbalanced Growth of Streptomyces hygroscopicus
}

\author{
By DIETER RIESENBERG* AND FRIEDRICH BERGTER \\ Akademie der Wissenschaften der DDR, Forschungszentrum für Molekularbiologie und Medizin, \\ Zentralinstitut für Mikrobiologie und experimentelle Therapie. Beutenbergstrasse II. \\ Schliessfach 73, DDR-6900 Jena, GDR
}

(Receited 18 October 1983: revised 26 April 1984)

\begin{abstract}
A small-scale system was developed in which balanced growth of Streptomyces hygroscopicus occurred. Although the balanced growth, verified by corresponding increase of ATP, DNA. RNA, protein and mycelial length, was restricted to a relatively short period of the life cycle, it lasted for at least two doublings. The conditions for balanced growth could be altered by various treatments to induce imbalance. This system could be applied to study regulation in the mycelium under well-defined conditions.
\end{abstract}

\section{INTRODUCTION}

Cultures of unicellular bacteria grow exponentially under unrestricted conditions in a balanced manner, i.e. each component of the cells increases by the same factor (Maaløe \& Kjeldgaard, 1966). Analysis of balanced growth and of cellular responses after perturbations (shift up or shift down) have proved to be very useful for physiological studies. The aim of the present investigation was to study the regulation of balanced growth in Streptomyces hygroscopicus mycelium, particularly the metabolism and mode of action of nucleoside polyphosphates.

Streptomycetes have a complex life cycle which includes spore germination, development of individual hyphae, formation of substrate mycelium by hyphal elongation and branching, formation of aerial mycelium, and finally sporogenesis (Hopwood et al., 1973; Kalakoutskii \& Agre, 1976). The kinetics of germination and growth of $S$. hy'groscopicus have been studied under surface (Schuhmann \& Bergter, 1976) and submerged (Riesenberg \& Bergter, 1979) conditions. After germination, the specific growth rate, determined by rates of apical growth and branching. was constant for several doublings of mycelial length and biomass, although the specific growth rate later declined. Other actinomycetes (Kretschmer, 1978) and fungi (Righelato. 1979) behaved similarly. Growth declined due to mycelial differentiation characterized by different metabolic activities in various mycelial regions such as the apex, branching region and the distal non-branching parts. Experimental results regarding the physiology and growth of streptomycetes are difficult to interpret since they are derived from the whole mycelium and cannot be ascribed to specific mycelial regions. Furthermore, comparisons with unicellular bacteria require caution since such bacteria multiply by complete cell division and do not. therefore, differentiate during ageing.

We have assumed that streptomycete cultures exhibit a restricted period of balanced mycelial growth after germination. In this paper we describe the conditions under which mycelia of $S$. hygroscopicus grow for at least two doublings in a balanced manner. In this well-defined system, mycelial responses after disturbances of balanced growth were reproducible. Our system proved 
to be useful for investigation of carbon source shift down and amino acid starvation in $S$. hygroscopicus (Riesenberg et al., 1984).

\section{METHODS}

Strain. Streptomyces hygroscopicus IMET JA 6599 (wild-type) from the culture collection of the Central Institute of Microbiology and Experimental Therapy (Jena) was obtained from Dr H. Prauser.

Media. Shift down medium (Tris/GSD medium) contained the following components per litre: $4.7 \mathrm{~g} \mathrm{NaCl}$, $1.1 \mathrm{~g} \mathrm{Na}_{2} \mathrm{SO}_{4}, 41 \mathrm{mg} \mathrm{MgCl}, 6 \mathrm{H}_{2} \mathrm{O}, 5.4 \mathrm{mg} \mathrm{FeCl}, 4 \mathrm{mg} \mathrm{MnCl}, 20 \mathrm{mg} \mathrm{CaCl}_{2}, 20.4 \mathrm{mg} \mathrm{KH_{2 }} \mathrm{PO}_{4}$, $118 \mathrm{mg}$ $\mathrm{NH}_{4} \mathrm{Cl}, 0.4 \mathrm{~g}$ glucose and $4.8 \mathrm{~g}$ Tris (Serva, FRG). Shift down medium (MOPS/GSD medium) buffered with

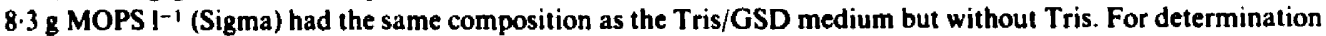
of substrate yield coefficients and for optimization of growth, the concentrations were varied as indicated in the text. All media were adjusted to $\mathrm{pH} 7.0$ and sterilized by filtration.

Grow'th conditions. Rapid spore germination and subsequent growth without clumping for at least five doublings was achieved by incubating $S$. hygroscopicus at $28^{\circ} \mathrm{C}$ in a glass tube $(13 \mathrm{~mm}$ internal diameter) containing $5 \mathrm{ml}$ Tris/GSD medium or MOPS/GSD medium. For aeration and mixing, air was bubbled through a hypodermic stainless steel needle ( $150 \times 120$, MLW Injecta, Klingenthal, GDR). A spore suspension pretreated for $10 \mathrm{~min}$ at $50^{\circ} \mathrm{C}$ served as inoculum to give a final spore titre of $3 \times 10^{7}$ spores $\mathrm{ml}^{-1}$. Growth could be followed without sampling simply by placing the glass tube in the TR accessory of a Spekol spectrophotometer (VEB, Carl Zeiss Jena, GDR) and then measuring the intensity of the light $(470 \mathrm{~nm})$ scattered by the culture at an angle of $45^{\circ}\left(I_{45}\right.$. $)$.

Preparation of spores. Frecze-dried spores were spread on agar slants (AL53) which had the following composition per litre: $3 \mathrm{~g}$ sucrose, $15 \mathrm{~g}$ dextrin, $1 \mathrm{~g}$ urea, $5 \mathrm{~g} \mathrm{NaCl}, 0.5 \mathrm{~g} \mathrm{KH} \mathrm{PO}_{4}, 1 \mathrm{~g}$ yeast extract, $5 \mathrm{~g}$ peptone. $10 \mathrm{mg} \mathrm{FeSO}{ }_{4}$, adjusted to $\mathrm{pH} 6.9$ prior to sterilization at $120^{\circ} \mathrm{C}$ for $35 \mathrm{~min}$. After 10 to $14 \mathrm{~d}$ at $28^{\circ} \mathrm{C}$, sporulated aerial mycelia served as the inoculum for new agar slant cultures. Fourteen days later these cultures were used for the preparation of spore suspensions. Spores were collected by rolling glass beads over the aerial mycelia. After adding Tris/GSD medium or MOPS/GSD medium to the spore-coated beads and shaking to remove the spores from the beads, the suspension was filtered (Por-40-filter, VEB Schott \& Gen., Jena, GDR) to separate spores from hyphal fragments.

Determination of dry weight. Mycelia from four $5 \mathrm{ml}$ cultures were filtered through membrane filters (Sartorius SMII 306, $0.45 \mu \mathrm{m}$ ). The filters containing the mycelia were dried in a desiccator and weighed.

Morphological analysis. Microphotography and determination of hyphal length has been described previously (Riesenberg \& Bergter, 1979).

Radioactive labelling. To determine accumulation of DNA, RNA, protein and ATP in growing mycelia, L['4 C]leucine (194 MBq mmol $\left.{ }^{-1} \mathrm{ml}^{-1}\right), \quad\left[5-{ }^{-3} \mathrm{H}\right]$ uridine $\left(3.6 \mathrm{GBq} \mathrm{mmol}^{-1} \mathrm{ml}^{-1}\right), \quad\left[{ }^{3} \mathrm{H}\right]$ thymidine-6 (45 GBq mmol ${ }^{-1} \mathrm{ml}^{-1}$ ) (all from the Isotope Institute Prague, CSSR) and $\mathrm{KH}_{2}{ }^{3} \mathrm{PO}_{4}$ (185 $\mathrm{MBq} \mathrm{ml}^{-1}$, carrierfree) (Isocommerz, Berlin. GDR) were added to separate cultures growing in Tris/GSD medium. Sampling and further processing of the samples was as described by Riesenberg \& Kari (1981).

Statistical analj'sis. Regression analyses were calculated and tested for significance according to Sachs (1972). Tests of normality were done according to Davies (197I). A significance level of $5 \%$ was applied.

\section{RESULTS AND DISCUSSION}

\section{Optimization of culture conditions for balanced growth}

Culture device. Preliminary experiments were carried out with spore inocula in Tris/GSD medium and MOPS/GSD medium in different culture vessels.

No satisfactory results were obtained in reciprocally shaken cylindrical glass vials with different volumes. Some vials had a side arm cuvette for direct measurement of the optical density of the culture. In all cases mycelial clumping occurred independently of shaking frequency. I. Zimmermann (personal coinmunication) found that the presence of a bottom layer of agar, or addition of liquid agar to the medium resulted in a very loose filamentous growth of Streptomyces levoris. For $S$. hygroscopicus neither a layer of agar at the bottom of the glass vials nor addition of liquid agar at different final concentrations prevented mycelial clumping. Clumping was greatly reduced but not prevented by incubating the mycelium in conical flasks of different volumes, which were rotated in a New Brunswick gyrotory water bath shaker at speed mark 3. Clumping of the mycelium could be prevented for at least five doublings of biomass when spores were germinated and the growing hyphae were incubated in simple glass tubes. Growth was measured by light scattering, as described in Methods.

Influence of the concentrations of medium buffers on mycelial growth. Microscopic observations 
revealed a positive correlation between the concentration of Tris and the degree of mycelial clumping. Growth of $S$. hygroscopicus lowered the $\mathrm{pH}$ of the medium. A concentration of Tris of $4.8 \mathrm{~g}^{-1}$ was the lowest which still allowed growth without noticeable clumping and which buffered the medium efficiently for at least four doublings of biomass after germination. No mycelial clumping was observed in media containing the buffer MOPS at a final concentration of $8.3 \mathrm{~g} \mathrm{I}^{-1}$.

Influence of calcium ions and heat treatment of spore suspension on germination and growth. Hirsch \& Ensign (1976a) found a heat activation of Streptomyces viridochromogenes spores and a positive effect of calcium ions on germination. The separate influences of calcium ions ( $20 \mathrm{mg} \mathrm{CaCl} \mathrm{I}^{-1}$, according to Hirsch \& Ensign, 1976a) and of heat treatment of the spore suspension $\left(10 \mathrm{~min}\right.$ at $\left.50^{\circ} \mathrm{C}\right)$ on germination of $S$. hygroscopicus spores and on subsequent growth in Tris/GSD medium and MOPS/GSD medium were determined. Both heat treatment and calcium ions shortened the duration of germination and increased the growth rate of the germinated mycelia. A combination of the two treatments gave the optimum result, i.e. the shortest germination time and the highest specific growth rate (data not shown). Therefore, subsequent experiments were performed in calcium-supplemented media and the spore suspension was always heat treated.

\section{Germination and grow'th of $S$. hygroscopicus}

Fig. I shows germination of a heat-treated spore suspension in Tris/GSD medium. A similar germination pattern was obtained for MOPS/GSD medium. The time of appearance of the first germlings depended on the age of the agar slant as well as on inoculum size; in the experiment shown in Fig. 1 it was $8 \mathrm{~h}$ (variation : 7 to $12 \mathrm{~h}$ ). Spores did not germinate synchronously as the period of germ tube formation lasted $3 \mathrm{~h}$. Germination was not associated with a temporary decrease of intensity of scattered light, as was found for absorption of light (Attwell \& Cross, 1973; Hirsch \& Ensign, 1976b; Hardisson et al., 1978; Riesenberg \& Bergter, 1979).

To show that measurement of intensity of scattered light $\left(I_{\downarrow 5}\right)$ corresponded to actual mycelial growth, the mean hyphal length $(L)$ of 30 to 60 individual mycelia was determined at different times of cultivation. Statistical comparison of the slopes of regression lines of $I_{45}$. for $11<t<$ $15 \mathrm{~h}$ and of $L$ for $10<t<15 \mathrm{~h}$ revealed no difference at a significance level of $5 \%$. The strong positive correlation between $I_{45}$. and $L$ was also shown by the high correlation coefficient $(R=$ $0.9996)$ from regression analysis. Therefore, measurement of $I_{45}$. could be used as a measure of mycelial growth under our experimental conditions. However, this was valid only in the phase of exponential increase of $I_{\downarrow s}$ and until $L$ was $70 \mu \mathrm{m}$.

The growth of $S$. hygroscopicus and incorporation of $\mathrm{KH}_{2}{ }^{32} \mathrm{PO}_{4},\left[{ }^{3} \mathrm{H}\right]$ thymidine, $\left[{ }^{3} \mathrm{H}\right]$ uridine and $\left[{ }^{3} \mathrm{H}\right]$ leucine into ATP, DNA, RNA and protein, respectively, are shown in Fig. 2 . After about two doublings of $I_{45}$, radioactivity was incorporated into ATP, DNA, RNA and protein at the same rate. This was verified by statistical analysis at the $5 \%$ significance level of the slopes of regression lines for ATP, DNA. RNA, protein and intensity of scattered light, in the cultivation period between 13.5 and $17 \mathrm{~h}$. In this restricted period we considered the growth to be balanced in the sense of Maaløe \& Kjeldgaard (1966).

The culture conditions under which $S$. hygroscopicus grew in a balanced manner had to be strictly maintained, otherwise mycelial clumping prevented balanced growth. This was especially important for the cultivation device, although we cannot explain why mycelial clumping occurred in reciprocally shaken cylindrical glass vials, but could be avoided by using glass tubes with aeration.

\section{Disturbance of balanced growth}

The response to perturbations in growth conditions by bacteria growing in a balanced manner has been used to investigate regulatory processes. Growth can be perturbed by exhaustion of a substrate in the culture medium. Therefore, we determined the yield coefficients of $S$. hygroscopicus for carbon and nitrogen sources, and investigated the action of certain substrate analogues, e.g. methyl $\alpha$-D-glucopyranoside ( $\alpha$-methylglucoside, $\alpha M G$ ) and DL-serine hydroxamate (SHX) on growth. 


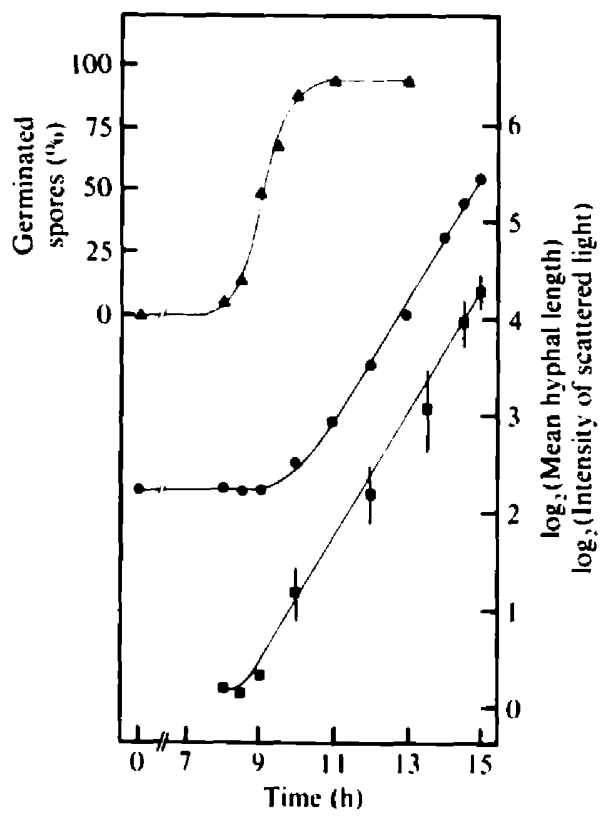

Fig. 1

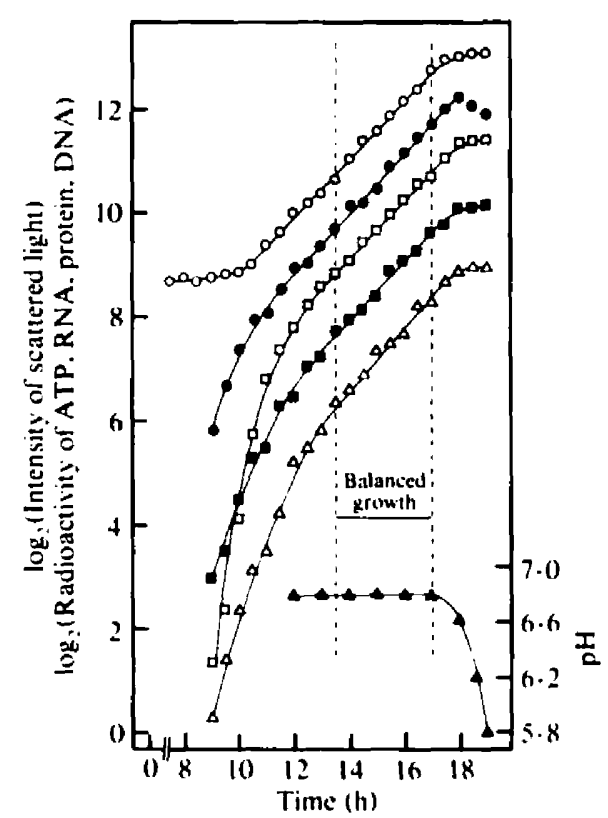

Fig. 2

Fig. 1. Germination of $S$. hygroscopicus spores. $\Delta$, Germinated spores $(\%)$; intensity of scattered light: $\square$. mean length of mycelia, with confidence intervals based on significance level of $5 \%$. Initial values: mean hyphal length, $2.3 \mu \mathrm{m}$; intensity of scattered light, 9 units.

Fig. 2. Growth of $S$. hygroscopicus. Four glass tubes containing Tris/GSD medium were inoculated with samples of a common prepared spore suspension and subsequently treated as described under Methods. Growth of each culture was measured by intensity of scattered light (O). pH was measured (A). At $t=9 \mathrm{~h} . \mathrm{KH}_{2}{ }^{32} \mathrm{PO}_{4},\left[{ }^{3} \mathrm{H}\right]$ uridine, $\left[{ }^{1+} \mathrm{C}\right]$ leucine and $\left[{ }^{3} \mathrm{H}\right]$ thymidine were added separately to the glass tubes and incorporation was followed into ATP (O). RNA ( $\square)$, protein ( $)$ ) and DNA $(\triangle)$. For specific activities of labelling see Methods. Values are given in a semilogarithmic scale and are displaced for clarity. Initial values were: ATP, $139 \mathrm{pmol} \mathrm{m}^{-1}$ : RNA, 40 c.p.m.: protein, 124 c.p.m. : DNA, 97 c.p.m. ; intensity of scattered light, 8 units. The curves during balanced growth represent the calculated regression lines.

Determination of yield coefficients of glucose, ammonium and phosphate. Yield coefficients $(Y)$ were calculated from the amount of substrate used $\Delta S\left(\mathrm{~g}^{-1}\right)$ to give an increase in cell mass, $\Delta X\left(\mathrm{~g}^{-1}\right)$, according to $Y=\Delta X \Delta S^{-1}$. These yield coefficients, $Y_{\text {glucose }}=0.45$ and $Y_{\mathrm{NH}_{i}}=$ 5.8, for $S$. hygroscopicus were in very good agreement with those of Escherichia coli (Pirt, 1975). To enable an efficient labelling of cellular components with ${ }^{32} \mathrm{P}_{\text {, we }}$ also determined the yield coefficient of phosphorus, $Y_{\mathrm{P}} \simeq 60$, but this value was not reproducible.

Treatment with $S H X$. After addition of SHX at a concentration of $2.5 \mathrm{mg} \mathrm{ml}^{-1}$ to an exponentially growing culture of $S$. hygroscopicus, further growth was prevented.

Treatment with $\alpha M G$. In $E$. coli $\alpha M G$ was taken up from the medium by the phosphotransferase system to form $\alpha$ MG 6-phosphate. It was not metabolized further (Kessler \& Rickenberg, 1963). The decreased uptake of glucose after addition of $\alpha \mathrm{MG}$ created the carbon source shift down. $\alpha$ MG was also active in Klebsiella pneumoniae (Riesenberg \& Kari, 1981). In $S$. hygroscopicus, $\alpha M G$ resulted in reduction of specific growth rate (Fig. 3). A negative correlation was found between the concentration of $\alpha \mathrm{MG}$ and the specific growth rate, $\mu$, until $2 \mathrm{~h}$ after the shift:

$$
\mu=\left(\log _{2} I_{45^{\circ}, \ldots}-\log _{2} I_{45^{\circ}}\right)\left(t_{i+1}-t_{i}\right)^{-1} \ln 2
$$

(see upper insert of Fig. 3). Therefore, we concluded that $\alpha M G$ competed with glucose. The post-shift specific growth rates of cultures treated with $\alpha \mathrm{MG}$ at low concentrations $(<3 \cdot 2 \%)$ 


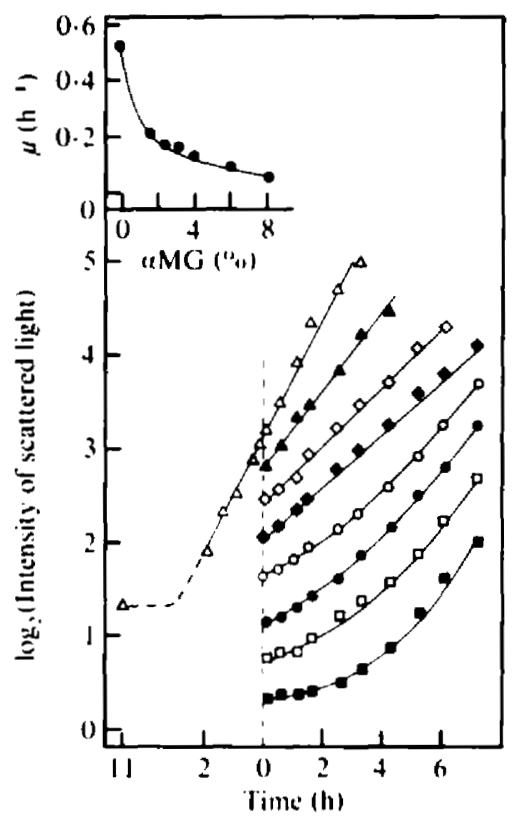

Fig. 3. Growth of $S$. hygroscopicus before and after treatment with $\alpha \mathbf{M G}$ at different concentrations.

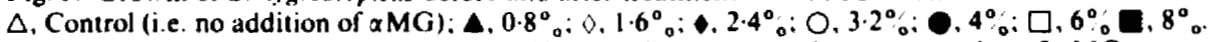
The inset shows the dependence of the specific growth rate, $\mu$, on the concentration of $\alpha \mathrm{MG}$. $\mu$ was calculated on the basis of regression lines in the time interval $0<t<2 \mathrm{~h}$.

were lower than the pre-shift specific growth rate and remained constant over two doublings. In cultures treated with $\alpha \mathrm{MG}$ at high concentrations $(>3.2 \%$ ), the culture grew, after a lag period, with a post-shift specific growth rate comparable with $\mu$ of the control culture. Probably, $\alpha \mathrm{MG}$ at high concentrations triggered the synthesis of an enzyme splitting glucose from $\alpha \mathrm{MG}$. Such an enzyme was found in bacilli by Harris \& Miller (1976).

The system developed, suitable for analysis of balanced and unbalanced growth of $S$. hygroscopicus, has been successfully applied for studying the effect of $\alpha \mathrm{MG}$ as well as the effect of SHX on nucleoside polyphosphate pools, RNA and protein accumulation in this mycelium forming bacterium (Riesenberg et al., 1984).

The technical help of Mrs Jutta Günther is gratefully acknowledged.

\section{REFERENCES}

Attwell, R. W. \& (Ross. T. (1973). Germination of actinomycete spores. In Actinomicetales: Characteristics and Practical Importance, pp. 197 207. Edited by G. Sykes \& F. A. Skinner. New York \& London: Academic Press.

DAvies. R. G. (1971). Computer programming in quantitatite hiolog!: New York \& London: Academic Press.

Hardisson, C., Manzanal, M. Salas, J. \& Starez. J. (1978). Fine structure, physiology and biochemistry of arthrospore germination in Sireptomlces antibioticus. Journal of General Microbiology 105, 203-214.

HARRIS. P. \& MilLer. E. K. (1976). Growth of bacilli on methyl- $\alpha$-D-glucoside. Nature. London 260, 4.32 433.

Hirsch, C. F. \& ENSIGN, J. C. (1976a). Heat activation of Streptomyces riridochromogenes spores. Journat of Bacteriolog! 126, $24,30$.

HiRsCh, C. F. \& Ensign, J. C. (1976b). Nutritionally defined conditions for germination of Streptomyces liridochromogenes spores. Journal of Bacteriolog! 126. 1323 .

Hopwood, D. A.. (hater, K. F.. Dowding, J. E. \& VIVIAN. A. (1973). Advances in Streptomyctes coelicolor genetics. Bacteriological Reriew's 37, 371405.

KaLAKOL'TSKII, L. V. \& AGRE. N. S. (1976). Comparative aspects of development and differentiation in actinomycetes. Bacteriological Rerien's 40, 469.524.

Kessler. D. P. \& Rickenberg. H. V. (1963). The competitive inhibition of $x$-methylglucoside uptake in Escherichia coli. Biochemical and Biophysical Research Communications 10, 482487. 
KRETSCHMER, S. (1978). Kinetics of vegetative growth of Thermoactimomyces vulgaris. Zeitschrift fuir Allgemeine Mikrobiologie 18, 701-711.

MaAloe, O. \& KJeld GaArd, N. O. (1966). Control of macromolecular synthesis. New York \& Amsterdam: Benjamin.

PIRT, S. J. (1975). Principles of microbe and cell cultivation. Oxford, London. Edinburgh \& Melbourne: Blackwell.

Riesenberg, D. \& Bergter, F. (1979). Dependence of macromolecular composition and morphology of Streptomyces hygroscopicus on specific growth rate. Zeilschrift für Allgemeine Mikrobiologie 19, 415-430.

Riesenbero, D. \& KARI, C. (1981). Isolation and characterization of prototrophic relaxed mutants of Klebsiella pneumoniae. Molecular and General Genetics 181, 476-483.

Riesenderg, D., Bergter, F. K Kari, C. (1984).
Effect of serine hydroxamate and $\alpha$-methylglucoside treatment on nucleoside polyphosphate pools, RNA and protein accumulation in Streptomyces hygroscopicus. Journal of General Microbiology 130, 25492558.

Righelato, R. C. (1979). The kinetics of mycelial growth. In Fungal Walls and Hyphal Growth, pp. 385-401. Edited by J. H. Burnett \& A. P. J. Trinci. Cambridge, New York \& Melbourne: Cambridge University Press.

SACHS, L. (1972). Statistische Auswertemethoden. 3. Auflage, p. 341. Berlin, Heidelberg \& New York: Springer Verlag.

SChuhMANN, E. \& Bergter, F. (1976). Mikroskopische Untersuchungen zur Wachstumskinetik von Streptomyces hygroscopicus. Zeitschrift für Allgemeine Mikrabiologie 16, 201-215. 